\title{
A comprehensive approach to the central monitoring of clinical trials
}

\author{
Julie Bakobaki ${ }^{*}$, Sally Stenning ${ }^{2}$, Nicola Joffe ${ }^{2}$, Sarah Meredith ${ }^{2}$ \\ From 3rd International Clinical Trials Methodology Conference \\ Glasgow, UK. 16-17 November 2015
}

\section{Background}

As part of a broader methodological programme of work around clinical trial monitoring, we plan to develop a comprehensive central monitoring strategy that is useful to staff developing clinical trial quality management and monitoring plans. In order to facilitate trial operation's staff planning a monitoring strategy where procedural and protocol compliance issues can be identified without the need to perform costly and intensive routine on-site data monitoring, we engaged in the current work that explores practical methods to achieve the aims of trial monitoring and trial conduct oversight.

\section{Methods}

The current work comprises of 3 components: a literature review; informal interviews and surveys of current practice by trial teams at a large UK Clinical Research Collaboration (UKCRC) registered Clinical Trials Unit engaging in phase II and III clinical trials in cancer and HIV research; and strategy development.

\section{Results}

At the time of writing this work is still being conducted. We aim to develop our strategy from the information available from all sources with suggestions for activities centred around: preventing, identifying, monitoring and addressing patient safety and participant rights issues; ensuring, through appropriate trial design and management, the generation of unbiased, accurate and timely data; enhancing trial management processes (including identifying poor performing sites and sites requiring additional support), enhancing protocol compliance, enhancing procedural compliance; and identifying fraudulent activities (fabrication or falsification of data).

${ }^{1}$ Comprehensive Clinical Trials Unit at UCL, London, UK

Full list of author information is available at the end of the article
Authors' details

${ }^{1}$ Comprehensive Clinical Trials Unit at UCL, London, UK. ${ }^{2}$ MRC Clinical Trials

Unit at UCL, London, UK.

Published: 16 November 2015

doi:10.1186/1745-6215-16-S2-P173

Cite this article as: Bakobaki et al:: A comprehensive approach to the central monitoring of clinical trials. Trials 2015 16(Suppl 2):P173.

\author{
Submit your next manuscript to BioMed Central \\ and take full advantage of: \\ - Convenient online submission \\ - Thorough peer review \\ - No space constraints or color figure charges \\ - Immediate publication on acceptance \\ - Inclusion in PubMed, CAS, Scopus and Google Scholar \\ - Research which is freely available for redistribution

C Biomed Central

C 2015 Bakobaki et al. This is an Open Access article distributed under the terms of the Creative Commons Attribution License (http:// creativecommons.org/licenses/by/4.0), which permits unrestricted use, distribution, and reproduction in any medium, provided the original work is properly cited. The Creative Commons Public Domain Dedication waiver (http://creativecommons.org/publicdomain/ 